\section{Tiago Pedó1*}

Tiago Zanatta Aumonde ${ }^{1}$

Leandro da Conceição Oliveira ${ }^{2}$

Leonardo Nora ${ }^{1}$

Carlos Rogério Mauch ${ }^{1}$

${ }^{1}$ Universidade Federal de Pelotas - UFPel, Campus

Universitário, 96010-900, Pelotas, RS, Brasil

${ }^{2}$ Instituto Federal Sul-rio-grandense - IFSul, Av.

Ildefonso Simões Lopes, 2791, Bairro Arco-íris,

Campus Pelotas-Visconde da Graça, 96060-290,

Pelotas, RS, Brasil

**:Parte integrante da Dissertação de Mestrado do primeiro autor. Mestrado financiado pelo CNPq.

Autor Correspondente:

"E-mail: tiago.pedo@gmail.com

\section{PALAVRAS-CHAVE}

Solanum lycopersicum L.

Distribuição

Produção

Pós-colheita

\section{KEYWORDS}

Solanum lycopersicum L.

Distribution

Production

Post-harvest

\section{NOTA CIENTÍFICA}

\section{Produtividade e características qualitativas do tomateiro submetidas à enxertia**}

\section{Yield and qualitative characteristics of grafted tomato}

RESUMO: Objetivou-se com este trabalho avaliar a produtividade, a classificação e a qualidade pós-colheita de frutos de plantas de tomate (cv. Gaúcho), e o enxerto destas plantas com plantas de tomate híbrido (cv. Kaguemusha), pelo método de estaca terminal. As plantas foram cultivadas em ambiente protegido, no município de Pelotas-RS, empregando-se delineamento experimental em blocos casualizados, com 20 repetições. Plantas de tomate enxertadas resultaram frutos com maior massa média (g) e fenóis totais, quando comparadas às não enxertadas.

ABSTRACT: The objective of this study was to evaluate the productivity, classification and postharvest quality of fruits of tomato plants (cv. Gaucho) and the grafting of these plants with hybrid tomato plants ( $c v$. Kaguemusha) by the terminal stake method. Plants were grown in a greenhouse in the municipality of Pelotas, state of Rio Grande do Sul (RS) using a complete randomized block design with 20 replications. Grafted tomato plants produced fruits with higher average weight $(g)$ and total phenols when compared to non-grafted plants. 


\section{Introdução}

O tomateiro é uma hortaliça de grande importância agronômica e econômica em todo o mundo. Atualmente, seu cultivo, no Brasil, apresenta produtividade crescente, superando a média de $63 \mathrm{t} \mathrm{ha}^{-1}$, em área superior a $60 \mathrm{mil}$ hectares (IBGE, 2009).

A cultura do tomateiro (Solanum lycopersicum L.) destaca-se como uma das principais hortaliças cultivadas no Brasil e, na dieta alimentar, figura como um importante aporte de vitaminas, sais minerais, sendo dotado de elevado efeito antioxidante. Contudo, a alta frequência de problemas fitossanitários que a cultura enfrenta em seu ciclo, em ambiente protegido (GOTO et al., 2010), tem levado ao estudo de novas técnicas, visando a superar esta problemática. Davis et al. (2008) destacam que o uso de plantas enxertadas acarreta ganhos de rendimento e, sobretudo, melhora a qualidade dos frutos colhidos.

Esta nova técnica objetiva aumentar a produtividade das culturas, aliada à melhoria das características pós-colheita dos frutos, e, fundamentalmente, contribuir para a superação de estresses abiótico e biótico (GOTO; SANTOS; CAÑIZARES, 2003). Segundo esses autores, os trabalhos relacionados com enxertia no Brasil iniciaram-se na década de 1980 e, até o presente momento, não foram efetuadas avaliações das contribuições relativas à enxertia para a qualidade e a produção de frutos de plantas enxertadas de tomateiro.

O objetivo deste trabalho foi avaliar a produtividade, a classificação e a qualidade pós-colheita de frutos de tomateiro enxertado e não enxertado (pé-franco).

\section{Material e Métodos}

O experimento foi realizado no Campus da Universidade Federal de Pelotas, no Município do Capão do Leão-RS.

A semeadura do porta-enxerto (híbrido Kaguemusha ${ }^{\circledR}$ ) foi realizada no dia 30/dez./2010, em recipientes de polietileno de $500 \mathrm{~mL}$, e o enxerto (Gaúcho $\left.{ }^{\circledR}\right)$, em 11/jan./2011, em bandejas de poliestireno expandido de 128 células. Para o preparo

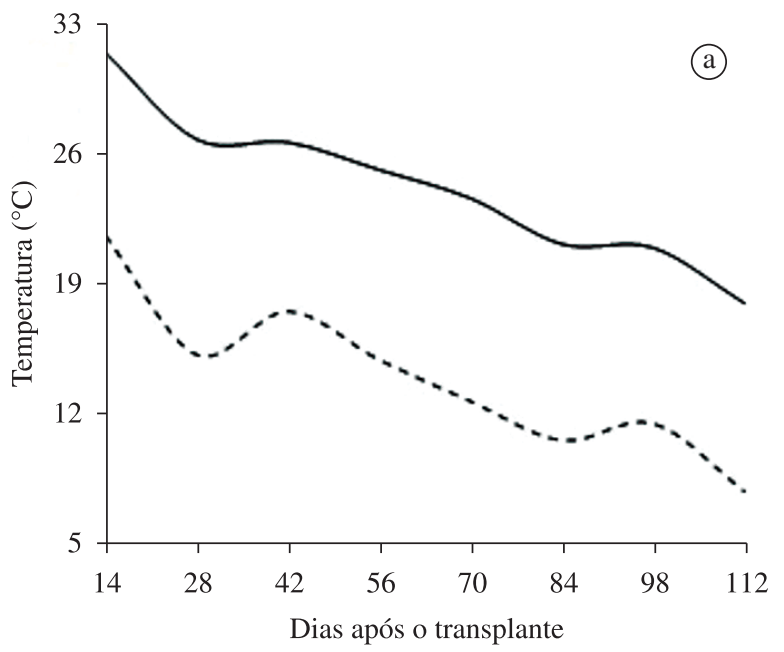

das mudas de tomateiro, o híbrido Kaguemusha e o enxerto Gaúcho, foi utilizado o substrato comercial H. Decker ${ }^{\circledR}$. A enxertia foi realizada em 30/jan./2011, pelo método de estaca terminal (GOTO; SANTOS; CAÑIZARES, 2003).

A produção das mudas e a avaliação da produtividade das plantas de tomateiro foram realizadas em casa de vegetação modelo arco, com sistema manual de abertura/fechamento das cortinas e com estrutura revestida com filme de polietileno de $150 \mu \mathrm{m}$ de espessura. A temperatura e a umidade relativa do ar foram obtidas por meio de termo-higrógrafo de registro semanal, instalado em abrigo meteorológico à altura de $1,5 \mathrm{~m}$ do piso e localizado no centro da casa de vegetação. As médias de temperatura mínima e máxima foram 13 e $36{ }^{\circ} \mathrm{C}$, enquanto as médias de umidade relativa mínima e máxima foram 65 e $93 \%$; os dados posteriores ao transplante são apresentados Figura 1.

As mudas foram transplantadas no dia 21/fev./2011, com a quinta folha definitiva aberta, espaçadas $0,40 \times 0,50 \mathrm{~m}$ em canteiros de $1,2 \times 5 \mathrm{~m}$, e com bordaduras laterais e frontais. Foi realizada a correção da acidez utilizando-se $20 \mathrm{~g} /$ canteiro de calcário com PRNT de 70\%, sendo incorporado ao solo para uma elevação da saturação até $82 \%$. A adubação do solo em cada canteiro foi efetuada pela aplicação de nitrato de cálcio em três parcelas de $30 \mathrm{~g}$, superfosfato triplo (148 g) e cloreto de potássio $(162 \mathrm{~g})$, para estimativa de produção de $75 \mathrm{t} \mathrm{ha}^{-1}$ (SBCS, 2004).

A adubação foi complementada com micronutrientes por meio do fertilizante foliar Torped ${ }^{\circledR}$. O solo foi coberto com filme de polietileno preto para controle de plantas daninhas e foi utilizado o sistema de tutoramento vertical de plantas (uma haste), com podas semanais não sendo realizada poda apical, e com irrigação realizada pelo sistema de irrigação localizada por gotejamento.

As colheitas foram realizadas a partir dos 84 dias após o transplante, totalizando três colheitas. Foram avaliadas a massa média dos frutos (g) e a produtividade não comercial, comercial e total, cujos dados foram expressos em $\mathrm{t} \mathrm{ha}^{-1}$. A classificação dos frutos foi obtida a partir do diâmetro

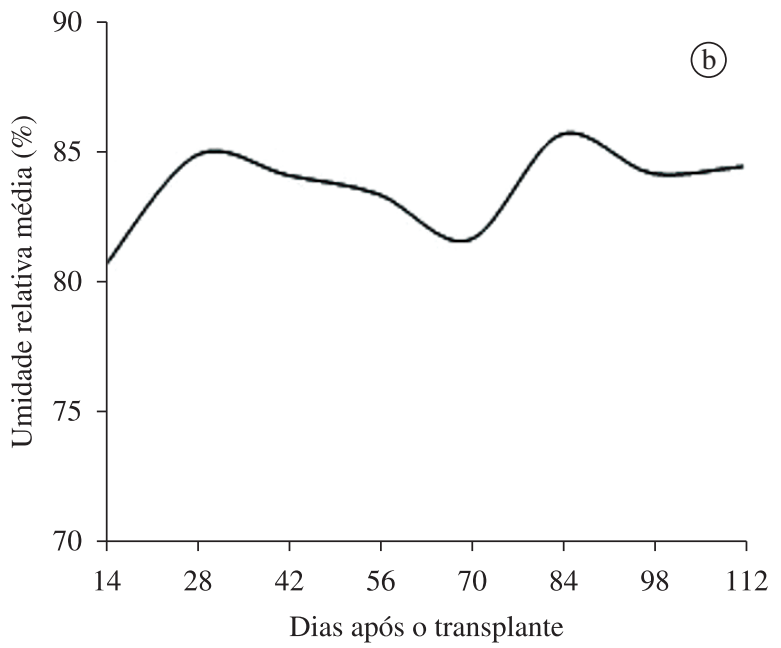

Figura 1. Temperatura (a) máxima ( — — ) e mínima ( - - - - - ) e umidade relativa (b) incidentes no interior da casa de vegetação em 2011. 
transversal, realizada com auxílio de paquímetro digital, de acordo com as normas do Ministério da Agricultura (Portaria no 553 MA, publicado no DOU de 19/09/95), segundo Loos, Caliman e Silva (2009), sendo: pequenos (50 $\leq \varnothing<65 \mathrm{~mm})$; médios $(65 \leq \varnothing<80 \mathrm{~mm})$; grandes $(80 \leq \varnothing<100 \mathrm{~mm})$, e gigantes $(\varnothing>100 \mathrm{~mm})$.

Os frutos, em número de cinco por repetição, depois de colhidos, foram submetidos à avaliação de pH em pHmetro marca Digimed MD 20; sólidos solúveis totais (SST) foram quantificados com refratômetro manual sem correção dos dados, marca AUS-JENA; acidez titulável total foi realizada por titulação com solução de $\mathrm{NaOH} 0,1 \mathrm{~N}$, tendo como indicador fenolftaleína, de acordo com AOAC (1992), expressa em (g $100 \mathrm{~g}^{-1}$ ) e calculada conforme a seguinte fórmula (Equação 1):

acidez $=(\mathrm{V} \times \mathrm{N} \times \mathrm{F} \times 100) / \mathrm{P}$

em que: $\mathrm{V}$ = volume da solução de $\mathrm{NaOH}$ gasto na titulaçao; $\mathrm{F}=$ fator de correção da solução de $\mathrm{NaOH} ; \mathrm{P}=$ massa em gramas da amostra; $\mathrm{N}=$ normalidade da solução de $\mathrm{NaOH}$.

A relação SST/ATT é obtida pela divisão dos sólidos solúveis totais pela acidez titulável total.

Foram quantificados os carotenoides totais, segundo o método descrito por Rodriguez-Amaya (2001), sendo aferidos $5 \mathrm{~g}$ de amostra e $2 \mathrm{~g}$ de celite. Adicionaram-se $20 \mathrm{~mL}$ de acetona, agitando-se o conteúdo por $10 \mathrm{~min}$. O material foi filtrado, lavando-se a amostra com acetona até que o extrato ficasse incolor. O filtrado foi transferido para um funil de separação, no qual se acrescentaram $30 \mathrm{~mL}$ de éter de petróleo e em torno de $100 \mathrm{~mL}$ de água destilada. O conteúdo de carotenoides foi determinado pela Equação 2:

$\mathrm{C}=\mathrm{ABS} \times 50 \mathrm{~mL} \times 106 / 2.500 \times 100 \times \mathrm{g}$ amostra

em que: $\mathrm{C}=$ concentração da amostra; $\mathrm{ABS}=$ absorbância.

Para quantificar os compostos fenólicos totais, conforme descrito por Singleton, Orthofer e Lamuela-Raventos (1999), aferiram-se $35 \mathrm{~g}$ de amostra previamente triturada e diluiu-se em $25 \mathrm{~mL}$ de metanol. A amostra foi homogeneizada a cada 5 min durante $1 \mathrm{~h}$, à temperatura ambiente. Filtrou-se com algodão, transferindo o homogeneizado para balão volumétrico de $50 \mathrm{~mL}$, completando-se o volume com metanol. Para clarificar o extrato aquoso, adicionaram-se $5 \mathrm{~mL}$ de solução de hidróxido de bário $0,1 \mathrm{M}$ e $5 \mathrm{~mL}$ de solução de sulfato de zinco a 5\%, ficando o conjunto em repouso por $20 \mathrm{~min}$, para então realizar uma centrifugação. Para realizar a quantificação dos fenóis totais, utilizaram-se $2 \mathrm{~mL}$ do extrato clarificado em espectrofotômetro (modelo Ultrospec 2000) a $765 \mathrm{~nm}$.
O experimento foi constituído de dois tratamentos (plantas de tomateiro enxertadas e não enxertadas), tendo sido instalado e conduzido no delineamento de blocos casualizados com vinte repetições para as análises de produtividade e cinco repetições para as características de pós-colheita. Os dados obtidos foram submetidos à análise de variância e a comparação de médias, ao Teste de Duncan, no nível de 5\% de probabilidade.

\section{Resultados e Discussão}

A massa média de frutos, que é componente importante das características produtivas, apresentou diferenças estatísticas entre plantas de tomate enxertadas e não enxertadas (Tabela 1). Tais diferenças devem-se ao fato de a enxertia influenciar a absorção e a translocação de nutrientes nas plantas, resultando em frutos de tamanho mais elevado quando comparados com os não enxertados e na melhora da qualidade dos frutos, o que foi observado no aumento do teor de fenóis totais (DAVIS et al., 2008). Corroborando com Çürük et al. (2009), a enxertia de plantas de berinjela aumentou a massa média de frutos, embora não tenha sido verificado tal aumento por Cardoso et al. (2006), em tomateiro. A enxertia não apresentou grandes alterações na distribuição dos frutos (Tabela 1), pois esta variável é mais influenciada por poda, raleio e densidade de plantas (MACHADO; ALVARENGA; FLORENTINO, 2007).

A produtividade total foi superior nas plantas não enxertadas (Tabela 1); entretanto, deve-se destacar que a produtividade comercial foi similar entre os tratamentos e que a produtividade não comercial foi maior nas plantas não enxertadas. Goto et al. (2010) obtiveram produtividade total inferior à obtida no presente trabalho, em se tratando de plantas de tomateiro enxertadas, demonstrando que a utilização da enxertia acarretou acréscimo na produtividade do tomateiro quando estes resultados são comparados aos encontrados na literatura. Loos, Caliman e Silva (2009) não obtiveram diferenças significativas na produtividade comercial ao comparar as plantas enxertadas com seus respectivos pés-francos (não enxertadas), o que vai ao encontro dos resultados obtidos. A produtividade similar pode ser explicada pelo fato de não ter sido constatada a ocorrência de patógenos, condição em que o porta-enxerto não pôde expressar suas características produtivas frente ao pé-franco (GOTO et al., 2010).

A qualidade dos frutos ( $\mathrm{pH}$ e acidez titulável total) não apresentou diferenças significativas entre os tratamentos (Tabela 2). A acidez titulável não é influenciada por técnicas e práticas de cultivo, sendo esta característica relacionada aos diferentes ambientes de cultivo, condizendo com os resultados encontrados para tomateiro (KHAH et al., 2006; CALIMAN et al., 2010). Resultados similares foram obtidos

Tabela 1. Massa dos frutos, classificação total dos frutos (\%) por classe de tamanho em função do diâmetro transversal ( $)$, produtividade não comercial (Perdas), produtividade de frutos comerciais e produtividade total de frutos de plantas de tomateiro enxertadas (Kag./Gaúcho) e não enxertada (Gaúcho). Pelotas, UFPel, 2011.

\begin{tabular}{|c|c|c|c|c|c|c|c|c|}
\hline \multirow{2}{*}{ Tratamento } & \multirow{2}{*}{$\begin{array}{c}\text { Massa } \\
\text { frutos }(\mathrm{g})\end{array}$} & \multicolumn{4}{|c|}{ Distribuição dos frutos (\%) } & \multirow{2}{*}{$\begin{array}{l}\text { Perdas } \\
\left(\mathrm{t} \mathrm{ha}^{-1}\right)\end{array}$} & \multirow{2}{*}{$\begin{array}{c}\text { Produtividade } \\
\text { comercial }\left(\mathrm{t} \mathrm{ha}^{-1}\right)\end{array}$} & \multirow{2}{*}{$\begin{array}{l}\text { Produtividade } \\
\text { total }\left(\mathrm{t} \mathrm{ha}^{-1}\right)\end{array}$} \\
\hline & & Pequeno & Médio & Grande & Gigante & & & \\
\hline Kag./Gaúcho & $229,3 \mathrm{a} *$ & $10,5 \mathrm{a}$ & $37,8 \mathrm{a}$ & $45,9 \mathrm{~b}$ & $5,8 \mathrm{a}$ & $23,7 \mathrm{~b}$ & $82,7 \mathrm{a}$ & $106,3 b$ \\
\hline Gaúcho & $208,7 b$ & $5,3 \mathrm{~b}$ & $37,3 \mathrm{a}$ & $55,7 \mathrm{a}$ & $1,7 \mathrm{~b}$ & $28,92 \mathrm{a}$ & $84,9 \mathrm{a}$ & $113,8 \mathrm{a}$ \\
\hline $\mathrm{CV}(\%)$ & 5,7 & 16,3 & 14,1 & 9,9 & 19,6 & 13,2 & 6,1 & 4,2 \\
\hline
\end{tabular}

*Médias seguidas com a mesma letra na coluna não diferem significativamente entre si, pelo teste de Duncan $(\mathrm{p} \leq 0,05)$. 
Tabela 2. Avaliação da qualidade pós-colheita de frutos de plantas de tomateiro enxertadas e não enxertadas, em relação a pH, acidez titulável total (ATT), sólidos solúveis totais (SST), relação SST/ATT, fenóis totais (FET) e carotenoides totais (CAT). Pelotas, UFPel, 2011.

\begin{tabular}{|c|c|c|c|c|c|c|}
\hline Tratamento & $\mathrm{pH}$ & $\begin{array}{c}\text { ATT } \\
\left(\mathrm{g} 100 \mathrm{~g}^{-1}\right) \\
\end{array}$ & $\begin{array}{l}\text { SST } \\
(\%) \\
\end{array}$ & $\begin{array}{c}\text { Relação } \\
\text { SST/ATT }\end{array}$ & $\begin{array}{l}\text { Fenóis } \\
\left(\mathrm{mg} \mathrm{g}^{-1}\right)\end{array}$ & $\begin{array}{c}\text { Carotenoides } \\
\left(\mathrm{mg} 100 \mathrm{~g}^{-1}\right)\end{array}$ \\
\hline Kag./Gaúcho & $4,15 a^{*}$ & $0,54 \mathrm{a}$ & $3,84 \mathrm{~b}$ & $7,22 \mathrm{a}$ & $3,20 \mathrm{a}$ & $53,95 \mathrm{a}$ \\
\hline Gaúcho & $4,13 \mathrm{a}$ & $0,55 \mathrm{a}$ & $4,04 \mathrm{a}$ & $7,35 \mathrm{a}$ & $2,20 \mathrm{~b}$ & $45,66 a$ \\
\hline $\mathrm{CV}(\%)$ & 1,55 & 12,21 & 3,14 & 12,23 & 8,27 & 10,97 \\
\hline
\end{tabular}

*Valores com a mesma letra na coluna não diferem significativamente entre si pelo teste de Duncan $(\mathrm{p} \leq 5 \%)$.

por Khah et al. (2006), que verificaram que as plantas enxertadas foram semelhantes às não enxertadas. Cardoso et al. (2006) observaram efeito da enxertia sobre o $\mathrm{pH}$ do fruto do tomateiro cv. Santa Clara $(4,47)$ comparado à enxertada no híbrido Hawaii 7996 (4,04).

O teor de sólidos solúveis totais (SST) foi superior nas plantas não enxertadas (Tabela 2). Tal fato pode ser explicado em razão de as plantas enxertadas apresentarem frutos com maior massa média (Tabela 1) e, provavelmente, por causa de algum fator que interferiu na síntese de sacarose, afetando o acúmulo de açúcares nos frutos e alterando os SST dos frutos provenientes de plantas enxertadas, quando comparadas ao pé-franco (CALIMAN et al., 2010). Khah et al. (2006) não observaram efeito da enxertia sobre os sólidos solúveis totais em ambos os sistemas de produção. Este resultado ressalta que o processo de enxertia não afeta esta característica qualitativa, sendo observada a mesma tendência de redução dos SST em frutos de plantas de berinjela enxertadas em casa de vegetação (ÇÜRÜK et al., 2009).

A relação SST/ATT não foi afetada significativamente pela enxertia (Tabela 2). Os resultados são similares aos obtidos por Cardoso et al. (2006) e Loos, Caliman e Silva (2009). As plantas de tomateiro apresentaram efeito significativo para os fenóis totais e não foi apresentada diferença significativa quanto ao teor de carotenoides totais entre os tratamentos (Tabela 2). A biossíntese de carotenoides é afetada consideravelmente por fatores ambientais e pela nutrição das plantas; neste caso, esta diferença pode ser atribuida ao porta-enxerto (ABUSHITA; DAOOD; BIACS, 2000). Aumonde et al. (2011) também verificaram que frutos de plantas enxertadas de minimelancia atingiram maior quantidade de fenóis totais em relação ao pé-franco, sendo que o estresse ocasionado pela enxertia parece ser indutor no aumento da produção destes metabólitos secundários (GOTO; SANTOS; CAÑIZARES, 2003), quando frutos de plantas enxertadas assumem importante papel frente à crescente tendência pela procura de alimentos funcionais e nutracêuticos.

\section{Conclusões}

A enxertia influenciou a massa média de frutos, enquanto a distribuição de frutos não foi afetada. Embora a produtividade total tenha sido inferior nas plantas enxertadas, frutos destas plantas apresentaram maior teor de fenóis totais.

\section{Agradecimentos}

Ao CNPq, pela concessão de Bolsa de Mestrado ao primeiro autor.

\section{Referências}

ABUSHITA, A. A.; DAOOD, H. G.; BIACS, P. A. Change in carotenoids and antioxidant vitamins in tomato as a function of varietal and technological factors. Journal of Agricultural and Food Chemistry, v. 48, n. 6, p. 2075-2081, 2000. http://dx.doi.org/10.1021/ jf990715p

ASSOCIATION OF OFICIAL ANALYTICAL CHEMISTS - AOAC. Official methods of analysis of the Association of Official Analytical Chemists. 15. ed. Arlington: AOAC, 1992.

AUMONDE, T. Z.; LOPES, N. F.; PEIL, R. M. N.; MORAES, D. M.; PEDÓ, T.; PRESTES, S. L. C.; NORA, L. Enxertia, produção e qualidade de frutos do híbrido de mini melancia Smile. Revista Brasileira Agrociência, v. 17, n. 1-4, p. 42-50, 2011.

CALIMAN, F. R. B.; SILVA, D. J. H.; STRINGHETA, P. C.; FONTES, P. C. R.; MOREIRA, G. R.; MANTOVANI, E. C. Quality of tomatoes grown under a protected environment and field conditions. Idesia, v. 28, n. 2, p. 75-82, 2010.

CARDOSO, S. C.; SOARES, A. C. F.; BRITO, A. S.; CARVALHO, L. A.; PEIXOTO, C. C.; PEREIRA, M. E. C.; GOES, E. Qualidade de frutos de tomateiro com e sem enxertia. Bragantia, v. 65 , n. 2 , p. $269-274,2006$. http://dx.doi.org/10.1590/S000687052006000200008

ÇÜRÜK, S.; DASGAN, H. Y.; MANSUROĞLU, S.; KURT, Ş.; MAZMANOĞLU, M.; ANTAKLI Ö.; TARLA, G. Grafted eggplant yield, quality and growth in infested soil with Verticillium dahliae and Meloidogyne incognita. Pesquisa Agropecuária Brasileira, v. 44, n. 12, p. 1673-1681, 2009.

DAVIS, A. R.; PERKINS-VEAZIE, P.; HASSELL, R.; LEVI, A.; KING, S. R.; ZHANG, X. Grafting effects on vegetable quality. HortScience, v. 43, n. 6, p. 1670-1672, 2008.

GOTO, R.; SANTOS, H. S.; CAÑIZARES, A. L. Enxertia em hortaliças. São Paulo: Editora UNESP, 2003. 85 p.

GOTO, G.; SIRTORI, L. F.; RODRIGUES, J. D.; LOPES, M. C. Produção de tomateiro, híbrido momotaro, em função do estádio das mudas e da enxertia. Ciência e Agrotecnologia, v. 34 , n. 4, p. 961-966, 2010. http://dx.doi.org/10.1590/S141370542010000400023

INSTITUTO BRASILEIRO DE GEOGRAFIA E ESTATÍSTICA - IBGE. Produção Agrícola Municipal. Rio de Janeiro: IBGE, 2009. Disponível: <http://www.sidra.ibge.gov.br/bda/ tabela/listabl.asp?c=1612\&z=p\&o=24>. Acesso em: 14 set. 2011 . 
KHAH, E. M.; KAKAVA, E.; MAVROMATIS, A.; CHACHALIS, D.; GOULAS, C. Effect of grafting on growth and yield of tomato (Lycopersicon esculentum Mill.) in greenhouse and open-field. Journal of Applied Horticulture, v. 8, n. 1, p. 3-7, 2006.

LOOS, R. A.; CALIMAN, F. R. B.; SILVA, D. J. H. Enxertia, produção e qualidade de tomateiros cultivados em ambiente protegido. Ciência Rural, v. 39, n. 1, p. 232-235, 2009. http://dx.doi.org/10.1590/ S0103-84782009000100037

MACHADO, A. Q.; ALVARENGA, M. A. R.; FLORENTINO, C. E. T. Produção de tomate italiano (saladete) sob diferentes densidades de plantio e sistemas de poda visando ao consumo in natura. Horticultura Brasileira, v. 25, n. 2, p. 149-153, 2007. http://dx.doi.org/10.1590/ S0102-05362007000200004
RODRIGUEZ-AMAYA, D. B. A guide to carotenoid analysis in foods. Washington: ILST Press, 2001. 64 p.

SINGLETON, V. L.; ORTHOFER, R.; LAMUELA-RAVENTOS, R. M. Analysis of total phenols and other oxidation substrates and antioxidants by means of the Folin-Ciocalteau reagent. Methods in Enzymology, v. 299, p. 152-178, 1999. http://dx.doi.org/10.1016/ S0076-6879(99)99017-1

SOCIEDADE BRASILEIRA DE CIÊNCIA DO SOLO - SBCS. Comissão de Química e Fertilidade do Solo - CQFS. Manual de adubação e calagem para os Estados do Rio Grande do Sul e Santa Catarina. 10. ed. Sociedade Brasileira de Ciência do Solo, 2004. 400 p. 